\title{
Super-ovulated Chinese sika deer (Cervus Nippon) and assessment of embryo transfer at developmental stages
}

\author{
Zhao Jing ${ }^{1}$, Madolo Nkosikhona ${ }^{1}$, Lv Wenfa ${ }^{1}$, M.J. Bringans ${ }^{3}$,Wang Quankai ${ }^{1,2,4, ~ * ~}$ \\ ${ }^{1}$ Jilin Agricultural University, Changchun, China \\ ${ }^{2}$ Jilin Sino-KOK Academy of Animal Sciences, Changchun, China \\ ${ }^{3}$ LIC- Advanced Genetics, Canada \\ ${ }^{4}$ Jilin Agricultural University, Changchun, China
}

\section{Email address:}

13944125038@163.com (Wang Quankai),nkosikho1@gmail.com (Wang Quankai)

\section{To cite this article:}

Zhao Jing, Madolo Nkosikhona, Lv Wenfa, M. J. Bringans, Wang Quankai. Super-Ovulated Chinese Sika Deer (Cervus Nippon) and Assessment of Embryo Transfer at Developmental Stages. International Journal of Genetics and Genomics.

Vol.2, No. 2, 2014, pp. 13-18. doi: 10.11648/j.ijgg.20140202.11

\begin{abstract}
The Embryo transfer has been commercially recognized reproductive technique in the world. The study was conducted at a Jiutai local breeding deer farm in China. The breeding protocol was developed for embryo transfer in sika deer to be implemented at farm levels and under wild conditions. Success rates of the technique was measured through indicators like number of follicles developed as a result of a specific treatment protocol, super ovulation rates, and quality of embryos. The male sika deer (Cervus Nippon) were then selected in terms of semen quality, libido, and sperm productivity. Embryo recovery was performed by surgical technique, of which the percentage of the embryo developmental stages was measured, in terms of Blastocyst, Morula, Non-Fertilized. The Hinds (sample size $=12$ ) were synchronically induced by inserting a controlled internal drug release (CIDR)devices, injected with Follicle stimulating Hormone (FSH) i.m for 2-4days. The fertilization for hinds was achieved by natural mating after 4days after CIDR devices withdrawal. Embryo recovery was performed on Day 12(n=6) and Day13(n=6)of the breeding season. The major objective of this research was to evaluate the super- stimulation protocols and determine the frequency of recovered transferable embryo in sika deer. Nevertheless, there were no significant differences $\mathrm{P}<0.05$ between the numbers of corpus luteum, Follicles, Blastocysts and Morula from both uterine horns. The embryo recovery showed positive outcomes of blastocyst, morula for sustainable genetic banking of pure sika deer.
\end{abstract}

Keywords: Embryo Transfer, Super Ovulation, Cryopreservation, Sika Deer

\section{Introduction}

\subsection{Background}

In most cases deer farming and breeding interests in the conservation of various deer species involves application of embryo transfer (ET) procedures. Embryo transfer has been commercially recognized reproductive technique over 40 years (Solar et.al, 2007, Thibiera \& Gue'rin, 2000).The protocol was developed for embryo transfer in sika deer to be implemented at farm levels and under wild conditions. Success rates of this embryo based technique was measured through indicators like number of follicles developed as a result of a specific treatment protocol, super ovulation rates, quality of embryos and pregnancy rates. Embryo transfer is defined as that process when the embryo is removed by flushing from the horn of the uterus before implantation and transferred into the horn of the uterus of synchronized recipient (Szabari, 2008). The sika deer (Cervus nippon) is an important member of the native fauna in the eastern Asia and widely distributed into many other parts of the world (Mccorkell, 2006, McCullough et.al.2008,). Sika deer are known of play a vital role in agriculture and economic ramifications.

However, the sika deer species in China has declined, due to overhunting in the past (Wang et al, 2012, Wu et.al.2003).Historically, There has been close association or completion between, both positive and negative effects between humans and sika deer (Ohnishi et. al., 2009). In this respect, much hunting success either deer or humans suffered disproportionately, because of the development of modern technology, guns traps etc. Humans disturbances 
are shown to increase in sika deer populations, consequently driving them to extinction in the wild (McCullough et al,2009).

Commizol et al, (2000) stated that the ecosystems can be disturbed when a single species are removed because of human activities, habitat destruction, over-hunting or completion. Therefore aim of animal conservation is very important to maintain biodiversity because the removal of a single species can affect the functioning of entire ecosystem. Therefore, that greatly supports the ideal targets of embryo transfer as a reproductive technique for genetic improvements. Therefore; it is important to develop effective reproductive biotechnologies like embryo transfer (ET),in order to increase the population of sika deer(Wang et.al.,2012)

On the other hand embryo cryopreservation is also the fundamental process used to facilitate the storage, transport and dissemination of valuable genetics

(Saragusty et.al, 2006, FAO, 2012).

Furthermore, literature reported that China is the earliest country to use different deer parts as traditional medicines (McCullough et.al; 2008, Landesman, 1999). Currently, sika deer (Cervus nippon), wapiti (Cervus canadensis), white-lipped deer (Gervus albirostris) and sambar (Cervus unicolor), etc. are farmed in China for harvesting antlers and game animal (Landesman, 1999). Interestingly, some studies also reported that deer antler are crucial for curing most diseases such as osteoarthritis, osteoporosis, but relatively costly. (Elizondo et.al, 2010, Wang et.al, 2012) reported that in China sika deer (Cervus Nippon)is highly recognized for its productivity, due to the fact that their main products such as cold fresh venison, chilled venison, dry venison, venison sausage, and spiced braised pork etc.; the byproducts include deer blood, deer penis, deer bone, deer antler. The venison's ("meat of the kings") nutritional value is higher than beef, mutton, and pork. However, the morphology, anatomy, physiological characters and living environment plays a vital role in selection (Ohnishiet.al. 2009).

Sika deer also known to constitute a very rich genetic resource for Chinese deer industry. For that very reason, sika deer breed is suitable deer for various deer products. Sika deer in terms of its adaptability are also termed to survive on a poor quality diet, and known to eat relatively greater quantities of poor quality high fibre forage when compared to other species, like red deer that consume relatively greater quantities of several more highly palatable species. Nevertheless, sika deer and fallow deer are likely to reach higher densities than Red deer in any given area, irrespective of whether ungulates have been present in the past or not. Sika deer also pose the greatest challenge for control (Huffman, 2004). There is considerable anecdotal evidence indicating that recreational hunters find sika deer more difficult to hunt.

For purpose of this research the male sika deer was selected in terms of semen quality, libido, and sperm productivity. The percentage of embryos reaching a certain developmental stage was measured after synchronization. The breeding protocols were developed were based on the same techniques used in sheep and cattle, but of which inclusive of surgical embryo recovery following FSHinduced super ovulation.

The major objective of the present research was to evaluate the surgical embryo transfer (ET) as a reproductive technique program in China and the determination the super- stimulatory protocols of FSH in fresh, frozen and vitrified sika deer embryos.

\section{Materials and Methods}

\subsection{Study Area}

The project was conducted at Jiutai local deer farm composed of 2000deer, in Jilin Province, North East of China. It is situated at longitude of $44^{0} 09^{\prime} 05.38 \mathrm{~N}$, 125050 '25.55'E, with 180 metres above sea level. The area is characterized by thicket forest of Pine trees (Pinusarmandii), Shrubs and different grass species. The annual average temperature $4.7{ }^{0} \mathrm{C}$, average annual temperature is $39.5{ }^{\circ} \mathrm{C}$, the average diurnal temperature $12.3{ }^{\circ} \mathrm{C} ; \geq 10{ }^{\circ} \mathrm{C}$ accumulated temperature was $2,880{ }^{\circ} \mathrm{Cand}$ annual average rainfall of $577 \mathrm{~mm}$.

\subsection{Animals}

Hinds of sample size $\mathrm{N}=12)$ donors and two $(\mathrm{N}=2)$ stags were confined and assigned with stags during the experiment. Sika deer were fed highly nutritious diets, e, g corn silage, Carrot mixed ration adlibitum. Animals were chosen based on good pedigree, such high yield of antlers, high fertility rates .

\subsection{Synchronization and Multiple-Ovulations}

On Day 13(September) in the afternoon females were synchronized in the afternoon within 12 hourly interval with Follitropin-FSH- V- Bionche, intramuscular injection from Canada). Female donors were inserted with controlled internal drug releasing devices with FSH from day 13(Day=0 estrus) September-14 September (rutting season) containing the totalof $400 \mathrm{mg}$ for 2-4 days.

\subsection{Estrus Detection}

The fertilization for sika deer was achieved by natural mating. Estrus was detected by female showing mounting behavior. In particularly, rutting behavior in September was observed during day, especially copulation from the stags but, unfortunately we could not manage to observe at night. Behavioral response was observed through lordosis reflex (standing estrus), and recorded after CIDR was removed. Hinds were then divided into two groups, assigned with one stag per pen for mating.

\subsection{Embryo Recovery}

Embryo developmental stage was recovered through 
surgical technique. Donors were not allowed access to feed and water for at least 12 hours before surgery. Embryo recovery was performed with the hinds placed in a dorsally recumbent position on stretchers at a $50^{\circ}$ angle, with the head tilted downwards. The abdomen was shaved and disinfected with 75\% Alcohol and Iodine solution, washed and prepared for abdominal incision. After theincision the abdomen was disinfected with Saline solution ( $0.9 \%$ ) to minimize adhesions. The hinds were frequently anesthetized for surgical procedures. Recording involved determination the number of corpora luteum (CL), number of Follicles, and number of blastocysts, number of Morula (M) and Non-Fertilized (NF) from both uterine horns, respectively. The numbers of follicle were visual assessed to obtain grading (Grade A, B, C) number of degenerates (ND) and non-fertilized (NF). The uterine tract was then exteriorized and embryo recovery was performed by flushing each uterine horn wih $40 \mathrm{~mL}$ Dulbecc's phosphate bufferd saline (D-PBS) supplemented with $20 \%$ (v/v of bovine serum) (Soler et al., 2007). Blastocysts (B1), Morula (M) and Non-Fertilized(NF) were visual assessed after flushing, observed, and counted in the prepared medium in a petri dish of $1000 \mathrm{mM}$.Embryos that were flushed into the petri dish were then visualized under the embryoscope to assess their developmental stages including their morphology and viability (NZDFA, 2013, (Fienet al.,2012, Wang et.al.,2012). Eventually, after recovery the animals were sutured and all the donors received postoperative antibiotic treatments. The recovered embryos were then transferred in the an open pulled $\operatorname{straw}(0.25 \mathrm{ml})$ with $10 \%$ ethylene glycerol before they were plunged into liquid nitrogen at $-196^{\circ} \mathrm{c}$ for vitrification.

\subsection{Statistical Analysis}

The treatment groups were analyzed using Duncan's test with two way analysis of variance (ANOVA).The overall mean were used with SPSS and Excel. The developmental stages of embryo (Blastocyst (Bl), Morula (M) and Nonfertilized (NF) were analyzed, respectively

\subsection{Vitrification}

Embryo were vitrified using the open pulled straw (OPS) method discussed by (Soler.2007,Saki et.al.,2009,Saragusty et.al., 2006, Wang et.al.2012) with little modifications when compared to our research. In another study, Souza et al. (2007) described for the first time that embryo production followed by vitrification in wood bison (Bison bisonathabascae) could be able to recover the animal's genetic material.(Saki et.al.,2009,FAO,2012) reported vitrification procedure has got economic advantages, and tangible benefits for its high pregnancy rates, because no ice crystal formation through increased temperature speed conduction and no need of freezing equipment during the procedure.

\section{Results}

For data collection of our study of 12 hinds were used with specific treatment controls. The captive sika deer showed a positive behavioral response of FSH. However, there were differences at mating intervals of stags during estrus detection. Consequently; the ovarian responsiveness indicated that the production of embryos and offspring depends on the existing knowledge of the reproductive physiology of each particular species. Hence little is known about the physiology and the timings of the first stages of the animal (Burckhardt, 2006). Based on those results stipulated below the ovarian responsiveness was variable.

Table 1.Embryonic developmental of corpus luteum and Follicles through visual assessment.

\begin{tabular}{cccc}
\hline Day & Ovary & Corpus luteum & Follicles \\
\hline \multirow{2}{*}{13} & LEFT & $4.83 \pm 1.47 \mathrm{a}$ & $2.33 \pm 2.25 \mathrm{a}$ \\
& RIGHT & $4.67 \pm 1.63 \mathrm{a}$ & $3.67 \pm 1.37 \mathrm{a}$ \\
\multirow{2}{*}{12} & LEFT & $6.50 \pm 5.68 \mathrm{a}$ & $0.67 \pm 1.21 \mathrm{a}$ \\
& RIGHT & $4.50 \pm 2.59 \mathrm{a}$ & $1.83 \pm 2.23 \mathrm{a}$ \\
\hline
\end{tabular}

(a).Day of 13 and 12 of embryo recovery through visual assessment which include: Ovary Left and Right, number Corpus lutea(CL) and number of Follicles.

Table 2.Blastocysts, Morula and Non fertilized examined through embryscope.

\begin{tabular}{|c|c|c|c|c|c|c|c|c|}
\hline \multirow{2}{*}{ DAY } & \multirow{2}{*}{ Ovary } & \multicolumn{3}{|c|}{ Blastocycsts } & \multicolumn{3}{|c|}{ Morula } & \multirow{2}{*}{ (no- fertilized ) } \\
\hline & & $\mathbf{A}$ & B & $\mathbf{C}$ & $\mathbf{A}$ & B & $\mathbf{C}$ & \\
\hline \multirow{2}{*}{13} & LEFT & $3.17 \pm 2.64 \mathrm{a}$ & $0.00 \pm 0.00 \mathrm{a}$ & $0.00 \pm 0.00 \mathrm{a}$ & $2.17 \pm 1.60 \mathrm{a}$ & $0.67 \pm 1.03 \mathrm{a}$ & $0.00 \pm 0.00 \mathrm{a}$ & $0.33 \pm 0.52 \mathrm{a}$ \\
\hline & RIGHT & $5.83 \pm 3.43 \mathrm{a}$ & $0.00 \pm 0.00 \mathrm{a}$ & $0.00 \pm 0.00 \mathrm{a}$ & $1.17 \pm 1.60 \mathrm{a}$ & $0.83 \pm 0.98 \mathrm{a}$ & $0.33 \pm 0.82 \mathrm{a}$ & $1.00 \pm 1.26 \mathrm{a}$ \\
\hline \multirow{2}{*}{12} & LEFT & $7.50 \pm 2.74 \mathrm{a}$ & $1.17 \pm 1.83 \mathrm{a}$ & $0.00 \pm 0.00 \mathrm{a}$ & $3.33 \pm 3.44 \mathrm{a}$ & $0.83 \pm 1.60 \mathrm{a}$ & $0.00 \pm 0.00 \mathrm{a}$ & $0.50 \pm 0.84 \mathrm{a}$ \\
\hline & RIGHT & $4.00 \pm 4.82 \mathrm{a}$ & $0.50 \pm 1.22 \mathrm{a}$ & $0.00 \pm 0.00 \mathrm{a}$ & $1.17 \pm 1.47 \mathrm{a}$ & $0.00 \pm 0.00 \mathrm{a}$ & $0.00 \pm 0.00 \mathrm{a}$ & $0.33 \pm 0.82 \mathrm{a}$ \\
\hline
\end{tabular}

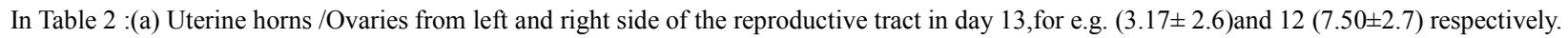
$0.00 \pm 0.00$ a indicates the zero recovery of embryos, where "a" represents the $\mathrm{P}<0.005$ not significant between the treatments.

(b)Representation the overall mean values that were generated by injection of FSH were blastocysts (a),(b),(c) that , Morula (a),(b),(c) and NF and their overall mean and standard deviation(Mean \pm SD) from Duncan's test 


\section{Discussion}

Based on the results obtained in this research, there was no significance difference $\mathrm{P}<0.005$ between the treatment groups (Jabbouret.al., 1994) .The could be multifactorial causes of differences in ovarian responsiveness and superstimulation of follicles. Behavioral response, time intervals with drug regimes/protocols of (FSH) could have effect. Moreover, embryo transfer (ET) technique has been regarded as one of the most complex with multiple factors associated with its success or failure (Abou-Setta, 2008, Mermillod et.al.,2006).For-instance the repeated starvation between Day 12 and 13 from donors could have caused a decrease follicle recovery and Morula. This decrease may be due to the fact that, there was repeated starvation of the donors before embryo recovery (Mermillod et.al., 2006).The abrupt withdrawal of feeding also needs to be investigated because stress induced during embryo recovery.

In Table (2), from the left side blastocysts stage average were different in day (13)mean values were $(5.83 \pm 3.43 \mathrm{a})$ and Day (12) $4.00 \pm 4.82 \mathrm{a}$ from the right side. Therefore one could observe there isn't much difference between standard deviation and Mean values. However, the overall means of morula(2.17 $\pm, 1.17 \pm 1.6,3.33 \mathrm{a}$ were significantly higher when compared to the Non-Fertilized(NF) $0.33 \pm, 0.50 \pm$, $1.00 \pm, 0.33 \pm$ )refer in Table (2).In some instances, long term weather problems or storms during the superovulation/recipient synchronization process are beyond the control of anyone and can wreak havoc with ET success. For an example, travel problems sometimes means traveling to a farm a day or two late, which mandates working with older embryos than planned. Probably the single most important variable affecting success in ET could be the level of donor and male reproductive efficiency. Many factors often go into cattle management and there are sometimes opportunities for ET practitioners to make a meaningful contribution in improving or changing certain management programs. Problems of low follicular oocyte population coupled with fragility of semen result in low cleavage rate and morula/blastocyst production(Madan et.al., 1994).In some cases, however, change either is not welcome or not possible and then the practitioner must make a short-hand way of the situation (Thibier \& Gue'rin, 2000).

On our findings (Table 2) showed that there were hinds that showed a large number of blastocyst (Grade A) $3.17 \pm 2.64 \mathrm{a}$ and Morula stages (Grade A) $1.17 \pm 1.60 \mathrm{a}$, the fertility from the stags could be the effect on such outcomes. Hence, some females consistently produced large numbers of embryos in response to super-ovulation, while other females of similar age, breed, management, etc., have performed poorly (Hasler, 2010). (Fennessy et.al 1994, Thibier \& Gue'rin 2000) reported that for successful responsiveness, it is also important that natural mating prior to the onset of normal breeding season, males also may need to be treated with subcutaneous melatonin. Hence, the increased circulation of melatonin in the blood minimizes the likelihood of anoestrus. Therefore, proven fertility of stags should be monitored for positive outcomes of embryo recovery. Embryo Transfer (ET) procedures are costly, thus experience and knowledge is essential. Because the low success rate of development to the blastocyst stage is increasing the cost of each embryo produced (Mermillod et.al.,2006, Thibier \& Gue'rin 2000)

\section{Funding}

This research was sponsored by international animal science and technology, co-operation project of China (2011DFA32900)

\section{Conclusion and Recommendation}

In conclusion the embryo recovery was successful, thus, can profoundly act as genetic resource banker and assist in achieving the goal of herd improvement and can be considered an important reproductive technique for conservation of genetic resources of farm animals or wild animals. Finally, encourage the growth of individual species and endangered breeds, minimizing challenges that are affecting negatively sika deer population. Therefore, embryo transfer could be a good option for conserving genetic diversity of pure sika deer, and that offers fastest way to restore an original breeding population, including both nuclear and mitochondrial genetic information. Embryo technology, however, is more advantageous because of lower disease transmition, but is usually more costly and requires greater technical capacity than gene banking with semen and one should also consider this technique with adequate financial budget.

\section{Acknowledgements}

We are grateful from Dr. Mike Bringans for his technical support and his technicians during Embryo recovery.

\section{References}

[1] Ashar, G. W Jabour H. N, Thompson, J.G Tervit H.R, Morrw C.J.1994. Superovulation of farmed red deer (Cervuselaphus) and fallow deer(Damadama): Incidence of Ovulation and changes in plasma hormone concentrations during the pre-ovulatory period in relation to ova recovery and fertilization. Newzealand Pastoral Agriculture Research Institute (Ag Research, Ruakura Agriculture Centre, Hamilton, New Zealand.(Abstra).

[2] Abou-Setta A. 2008. Optimizing the Embryo Transfer Technique .PhD Thesis, University of Amsterdam. Amsterdam Al Yacoub A.N, Gauly M, Holtz W .2010 .Open pulled straw vitrification of goat embryos at various stages of development. Department of Animal Science, GeorgAugust-University, Goettingen, Germany. Theriogenology. May; 73(8):1018\23.doi:10.1016/j.theriogenology.(Abstra) 
[3] Burckhardt h. A.2006. Incorporation of analgesics into Rodent embryo transfer protocols: assessing the effects on reproductive Outcomes. Thesis submitted to the office of graduate studies of texasa \& m university

[4] Commizol P, Mermillod P, Congnie Y, Chai N.2001. Succesful in vitro production of embryo in red deer(Cervuselaphus) and the sika deer(Cervus Nippon).45(2)649-59.MNHN Conservation des Especies Animales, France.

[5] Current progress in oocyte and embryo cryopreservation by slow freezing and vitrification Tainan (Taiwan, R.O.C.)(n.d), pges 7-10.

[6] FAO.2012.Cryoconservation of Animal Genetics Reseources. Animal Production and Health. Guidelines. Rome

[7] Fennessy P.F, Asher G.W., Beatson N.S., Dixon T.E., Hunter J.W., Bringans M.J 1994. An International Journal of Animal Reproduction. Proceedings of the Annual Conference of the International Embryo Transfer Society Embryo transfer in deer. Volume 41, (1), Pages 133-138. South Auckland, NZ, USA.

[8] Fennesy P. F, M. W, Fisher, J. R. Webster, C. G, Mackintosh(n.d), J. M Suttie, A. J Pearse and I.D Corson. Invermay Agriculture \& Fisheries, Mosgiel.

[9] Fennesy P. F, Asher N. S, Beatson T. E, Dixon J. W Hunter, Bringans M. J. 1994. Embryo transfer in Deer. Deer reproduction services. South Auckland.NZ

[10] Feldhammer G.A.1980. Cervus Nippon. The American society of mammalogists. pg1-7

[11] Huffman B.2004. The Cervus Nippon. Available at www.ultimateungulate.com.

[12] Hasler John F. 2010.Bovine embryo transfer: are efficiencies improving? Bioniche Animal Health, Inc.NE 1335 Terre View Dr. Pullman, WA 99163 US (Abstra.)

[13] Hong Q.H, Tian S.J, Zhu S.E, Feng J.Z, Yan C.L, Zhao X.M, Liu G.S, Zheng S.M.2007. Vitrification of boer goat morulae and early blastocysts by straw and open-pulled straw method. Reprod Domest Anim. 42(1):34-8.(Abstra.)

[14] Jabbour H .N, Marshall V.S, Argo C.M, Hooton J. and Loudon AS.1994. Successful embryo transfer following artificial insemination of super ovulated fallow deer (Damadama) Reproduction, Fertility and Development 6(2) $181-185$

[15] Landesman, N. 1999. "Cervusnippon" (On-line), Animal Diversity Web. Accessed March 31, 2014 at http://animaldiversity.ummz.umich.edu/accounts/Cervus_ni ppon/.University of Michigan.

[16] Luan X,Zhao C and Meng X,.2011.Behavioral differences between Captive Female Alpine Musk Deer with Reproduction in Previous Year. College of Nature Conservation, Beijing Forestry University, Beijing, China

[17] Mapletoft R. J.2010.Perspectives on Bovine Embryo Transfer .WCVM, University of Saskatchewan, Saskatoon, Saskatchewan Canada S7N 5B4 p.85-86
[18] Mermillod P., Locatelli Y., Dalbiès-Tran R., Uzbekova S., Baril G., Guignot F., Perreau C., Poulin N.,. TouzéJ. Pennetier L, S., Schmaltz B., and CogniéY. . 2006. In vitro production of ruminant embryos: Results, limits and perspectives Symposium COA/INRA Scientific Cooperation in Agriculture,

[19] Mc Cullough D. R, Takatsuki S, KajiK.2008.Silka: Biology Management of Native and Introduced. pges 686

[20] Mccorkell R. B.2006.Thesis in Endogenous and Exogenous Control of Ovarian Dynamics in Wapiti. Department of Veterinary Biomedical Sciences. University of Saskatcherwan. Saskatoon.

[21] Ohnishi N, Minam M , Nishiya R, Yamada K, Nishuzuka H, Higuchi H, Nara A, Suzuki M,Takatsuki.2009.Reproduction of female sika deer in Japan, with special reference to kinkazan Island, North Japan.pg 101-110

[22] Rev. sci. tech off.int.Epiz.1990. Reproductive technology in animal production. J.N Shelton the John Curtin School of Medical Research.. The Australian National-University,Development Clinicalal. Physiology Group, Divison of sciences. Australia. volume 9(3) 830-831

[23] Souza J.M.G, Ribrio I. T. P. Batista, Luciana M. Vicente .M, .Freitas J.F .2011.Reproductive biotechnologies applied to the conservation of endangered ruminant-past, present and future. Ceará State University (UECE) CEP: 60740-093, Fortaleza, CE, Brazil, RPCV (110 (577-580)

[24] Soler a J.P, Mucci N., Kaiser G. G., Aller J.. Hunter J.W ,Dixon T.E, Alberio R.H. Multiple ovulation and embryo transfer with fresh, frozen and vitrified red deer (Cervus elaphus) embryos in Argentina. Journal of Animal Reproduction Science 102 (2007) 322-327

[25] Saragusty J. and Arav. A .2011 .Department of Reproduction Management, Leibniz Institute for Zoo and Wildlife Research, Alfred-Kowalke-Strasse.17, D-10315 Berlin, Germany and 1Institute of Animal Sciences, Agricultural Research Organization, The Volcani Center, Bet Dagan, Israel.

[26] Saragusty J, Gacitua H, King R, Arav A .2006. Post-mortem semencryopreservation and characterization in two different endangered gazelle species (Gazellagazella and Gazelladorcas) and one subspecies (Gazellagazelleacaiae). Theriogenology,

[27] Saki G., Rahim F and Zergani J. M.2009.Vitrification of small Volume of Normal Human sperms:Use of Open Pulled Straw Carrier. Research Paper J.Med.sci. Volume 9(10:3035

[28] Thibier M., Gue'rin B.2000. Embryo transfer in small ruminants: the method of choice for health control in germplasm exchanges. Alfort. Livestock Production Science 62 253-270 France .BP 65, 94703

[29] Szabari.M.2008 Effects of embryo transfer on breeding of Holstein Friesian. University of Kaposvár.

[30] Venegas F; Guillomot M; Vignon X; Servely J.L; Audouard C;; Le Bourhis D. M. E; Perón Sandrine; Soto P Rojas M.Obtaiment of Pudu (Pudupudu) deer.2006. Embryos by the Somatic Nuclear Transfer Technique. Int. J. Morphol.,24(2): pges 285-292 
[31] Wang .LG.B. Zhou W.Q. Shi J. M. Shi, X. Z. Tian C. Gao, L. Zhang S. E. Zhu T. T. Zhang, S.M. ZengG.S. Liu (2012. Journal of Anima reproduction. First live offspring born in super ovulated sika deer (Cervus nippon) after embryo vitrification. Volume 78(7) pgs 1627-1632 .China Agricultural University.

[32] Windbank M. C. 2009. Interaction of hormones and nutrition on reproductive of dairy cows .professor of dairy science. University of wisconsin-madison.
[33] Yu Wenyuan.2008.Sika Deer Slaughtering and Meat Products Processing Project of Dongfeng County, Liaoyuan City. available at http://english.jl.gov.cn

[34] Zhou G.B, Hou Y.P, Jin F, Yang Q.E, Yang Z.Q, Quan G.B, Tan H.M, Zhu S.E .2005.Vitrification of mouse embryos at various stages by open-pulled straw (OPS) method. Laboratory of Animal Embryonic Biotechnology, China Agricultural University, China. 6316(2):153 